\title{
RATINGS OF CONSUMER SATISFACTION: THE CASE OF BBS-DIZAIN LTD
}

Inara Jurgena ${ }^{1}$, Dr.oec.; Aina Muska ${ }^{2}$, Dr.oec. and Elina Jurjane ${ }^{3}$, Mg.oec.

${ }_{1,2}$ Faculty of Economics and Social Development, Latvia University of life Sciences and Technologies, ${ }^{3}$ SIA „BBS Dizain"

Abstract. Entrepreneurship is based on meeting customer needs, which allows achieving the goals of the enterprise. In this process, the enterprise and the customer have their own goals they want to achieve: one of the goals of the enterprise is to attract and retain customers, whereas the customer wishes to purchase a product at the necessary place, time and quality and receive customer service of a wished quality.

The authors conducted a survey of internal and external customers of BBS-Dizain Ltd with the aim of identifying their satisfaction level according to quality criteria for the assortment of the enterprise's services and the imperfections to be eliminated.

The research determined the most important components of restaurant customer service for the customers of BBS-Dizain Ltd and the customer satisfaction level and made proposals for enhancing some of the components.

Key words: customer, satisfaction, quality.

JEL code: M210.

\section{Introduction}

Entrepreneurship is based on meeting customer needs, which allows achieving the goals of the enterprise. In this process, various relationships emerge between the enterprise and the customer, yet both sides have specific goals they pursue: the enterprise wants to attract and retain customers and increase its turnover, market share and profit, while the customer wishes to purchase a product at the necessary place, time and quality and receive customer service of a wished quality. The relationships are based on mutual gains. According to research investigations, attracting a new customer costs 5-10-fold more than selling the product to the current customer; besides, the current customer spends $67 \%$ more money than a new one does. Accordingly, meeting consumer needs is a priority for the enterprise (Linina, 2018).

The management of BBS-Dizain Ltd wished to identify the satisfaction level of their customers for the purpose of increasing the competitiveness of the enterprise. Nowadays, to ensure the development and competitiveness of an organisation, it is important to find new ways of work organisation and arrangement, enhance business processes and introduce innovations, which contribute to the productivity, quality and efficiency of labour.

The following hypothesis is put forward: customer ratings of their satisfaction give an enterprise an opportunity to enhance its business.

The research aim is to identify opportunities for enhancing the quality of restaurant services for BBS-Dizain Ltd based on customer satisfaction ratings.

To achieve the aim, the following specific research tasks are set: (1) to identify the satisfaction of customers with restaurant services provided by BBS-Dizain Ltd, (2) to perform an in-depth analysis of the lowest-rated component of the customer satisfaction tree identified while performing the first research task.

The research employed general, sociological and statistical analysis methods as well as marketing methods. The research used BBS-Dizain Ltd unpublished data for the period 1 January-31 August 2018 as well as primary data acquired by the authors while working on the present research.

\footnotetext{
${ }^{1}$ Inara.Jurgena@llu.Iv
} 


\section{Research results and discussion}

To identify the opinions of customers on the quality of services provided by the restaurant and the customer satisfaction index, the research, first of all, identified 15 components of the customer satisfaction tree (or the performance of the restaurant) for the analysed enterprise - BBS-Dizain Ltd.

Babris S. et al. (2016) point out that business efficiency requires active involvement of the management, employees and stakeholders in planning and introducing business enhancement activities and in performance tracking; therefore, the employees, industry experts and customers were involved in identifying the components.

Table 1

\section{Customer ratings of their satisfaction with the quality of services provided by BBS-Dizain Ltd}

\begin{tabular}{|c|c|c|c|c|c|c|c|c|c|}
\hline \multirow{2}{*}{$\begin{array}{l}\text { Consumer } \\
\text { satisfaction tree } \\
\text { components }\end{array}$} & \multicolumn{2}{|c|}{ Importance ratings } & \multicolumn{5}{|c|}{ Ratings of quality, points } & \multirow{2}{*}{$\begin{array}{c}\text { Average } \\
\text { rating of } \\
\text { quality }\end{array}$} & \multirow{2}{*}{$\begin{array}{c}\text { Customer } \\
\text { satisfactior } \\
\text { index }\end{array}$} \\
\hline & average & weight, \% & 5 & 4 & 3 & 2 & 1 & & \\
\hline Interior design & 3.02 & 4.7 & 62 & 38 & 0 & 0 & 0 & 4.62 & 100 \\
\hline Room arrangement & 3.44 & 5.4 & 96 & 4 & 0 & 0 & 0 & 4.96 & 100 \\
\hline Room tidiness & 4.82 & 7.6 & 89 & 11 & 0 & 0 & 0 & 4.89 & 100 \\
\hline $\begin{array}{l}\text { Arrangement of } \\
\text { tables }\end{array}$ & 4.01 & 6.3 & 8 & 84 & 8 & 0 & 0 & 4.00 & 92 \\
\hline Table decoration & 4.73 & 7.4 & 1 & 12 & 66 & 21 & 0 & 2.93 & 13 \\
\hline $\begin{array}{l}\text { Personnel } \\
\text { professionalism }\end{array}$ & 4.48 & 7.0 & 55 & 43 & 2 & 0 & 0 & 4.53 & 98 \\
\hline Personnel attitude & 4.89 & 7.7 & 88 & 10 & 2 & 0 & 0 & 4.86 & 98 \\
\hline $\begin{array}{l}\text { Available } \\
\text { assortment of } \\
\text { dishes }\end{array}$ & 4.71 & 7.4 & 81 & 18 & 1 & 0 & 0 & 4.80 & 99 \\
\hline Quality of dishes & 5.00 & 7.8 & 64 & 27 & 9 & 0 & 0 & 4.55 & 91 \\
\hline Size of a portion & 4.11 & 6.4 & 82 & 15 & 3 & 0 & 0 & 4.79 & 97 \\
\hline $\begin{array}{l}\text { Order completion } \\
\text { time }\end{array}$ & 4.90 & 7.7 & 11 & 31 & 54 & 4 & 0 & 3.49 & 42 \\
\hline Quality of drinks & 4.12 & 6.5 & 88 & 9 & 3 & 0 & 0 & 4.85 & 97 \\
\hline $\begin{array}{l}\text { Customer service } \\
\text { methods }\end{array}$ & 4.23 & 6.6 & 58 & 41 & 1 & 0 & 0 & 4.57 & 99 \\
\hline Payment system & 2.87 & 4.5 & 93 & 7 & 0 & 0 & 0 & 4.93 & 100 \\
\hline $\begin{array}{l}\text { Quality of customer } \\
\text { service }\end{array}$ & 4.46 & 7.0 & 42 & 52 & 6 & 0 & 0 & 4.36 & 94 \\
\hline Total & 63.79 & 100 & 918 & 402 & 155 & 25 & 0 & - & - \\
\hline $\begin{array}{l}\text { Quality rating } \\
\text { weight, } \%\end{array}$ & - & - & 61 & 27 & 10 & 2 & 0 & - & - \\
\hline Accrued weight, \% & - & - & 61 & 88 & 98 & 100 & 100 & - & - \\
\hline Average rating & - & - & - & - & - & - & - & 4.48 & 88 \\
\hline
\end{tabular}

Source: authors' calculations based on Kane M.M. et al., 2009

One hundred randomly chosen customers of the enterprise were requested to rate the IMPORTANCE of customer satisfaction tree components on a five-point scale ( 5 - very important, 4 - important, 3 - moderately important, 2 - slightly important and 1 - unimportant) as well as the performance or QUALITY of the components on a five-point scale (5 - very good, 4 - good, 3 acceptable, 2 - poor and 1 - very poor). The survey was conducted in the period 2-31 July 2018. The results are presented in Table 1.

As shown in Table 1, the most important components of performance of the restaurant were as follows: quality of dishes (5.00 points), order completion time (4.90), personnel attitude (4.89), 
room tidiness (4.82) etc. Moderately important components were as follows: the payment system (2.87), interior design (3.02) and room arrangement (3.44). An analysis of the customers' ratings of the quality of customer satisfaction tree components revealed that table decoration (2.93) and order completion time (3.49) were rated the lowest by the customers. The other components were rated at 4 or higher. The average rating of the quality of restaurant services was high -4.48 points.

The customer satisfaction index that was calculated based on all the customers who rated quality at 5 and 4 points (according to a methodology suggested by Kane M. M., Ivanov B. V., Koreskov V. N., Shirtladze A. G.) showed that overall, the customers were satisfied with the quality of the restaurant's services (customer satisfaction index $=88$ ) as well as with some performance components, particularly room interior design (index $=100$ ), room arrangement $(100)$, room tidiness $(100)$, the payment system (100) etc. The survey revealed that table decoration was rated very low (index=13 out of 100).

The survey questioned the restaurant's employees to establish their opinions about the customers' ratings of the quality of customer satisfaction tree components. The employees rated table decoration the lowest as well. The data acquired from both respondent groups were compared by employing contingency analysis to verify whether the ratings depended on respondent group. The hypotheses to be verified were as follows:

$H_{0}$ : No causal association between the ratings by the customers and the employees;

$H_{1}$ : there is a causal association between the ratings by the customers and the employees.

Since $\chi^{2}=12.23>\chi_{0.05 ; 3}^{2}, H_{0}$ has to be rejected and $H_{1}$ has to be accepted. This means that at a confidence level of $95 \%$, one can assume that there is an association between the ratings by the customers and the employees.

This implies that the respondents of both groups were unanimous regarding enhancement of table decoration.

To identify the baseline situation, the authors analysed the demand for tables by customers at the restaurant (Figure 1).

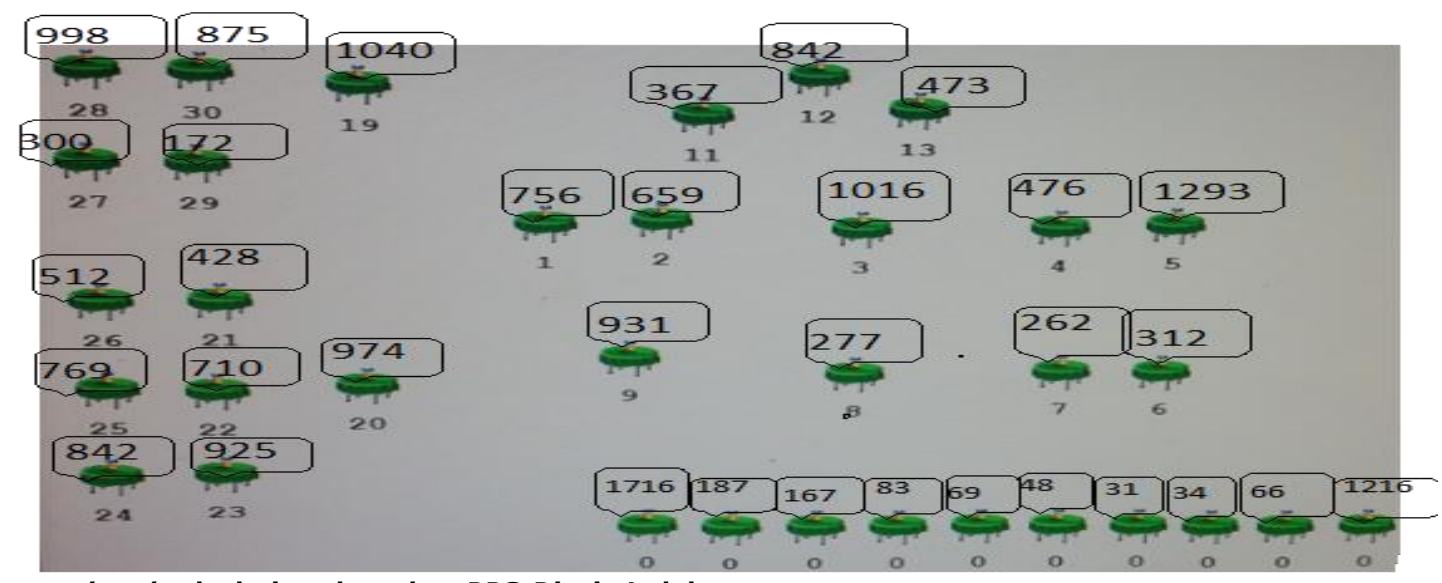

Source: authors' calculations based on BBS-Dizain Ltd data

Fig. 1. Number of customers served at tables at the restaurant of BBS-Dizain Ltd from 1 January to 31 August 2018

The data indicate that the most demanded tables were No. 5, 19 and 3. After analysing the locations of the tables, the surrounding environment and interior items and other aspects, the authors concluded that customers had an opportunity to "seclude themselves" at tables No. 5 and 9, as both tables were located in the corners of the room as well as the restaurant's window overlooked 
the well-arranged outside, while table No. 3 was placed at a fireplace, which was preferred by customers being romantics.

The authors made a Top 10 for tables both in terms of generalised revenue and in terms of number of customers served.

TOP 10 of restaurant tables in terms of generalised revenue and number of customers served by BBS-Dizain Ltd from 1 January to 31 August 2018

\begin{tabular}{|l|c|c|c|c|}
\hline Ranking & $\begin{array}{c}\text { Table } \\
\text { No. }\end{array}$ & $\begin{array}{c}\text { Revenue from the table, } \\
\text { EUR }\end{array}$ & $\begin{array}{c}\text { Table } \\
\text { No. }\end{array}$ & $\begin{array}{c}\text { Number of customers served } \\
\text { at the table }\end{array}$ \\
\hline 1. & 5 & 29394 & 5 & 1293 \\
\hline 2. & 3 & 21760 & 19 & 1040 \\
\hline 3. & 28 & 20707 & 3 & 1016 \\
\hline 4. & 19 & 20171 & 28 & 998 \\
\hline $\mathbf{5 .}$ & 20 & 20145 & 20 & 974 \\
\hline 6. & 23 & 19190 & 9 & 931 \\
\hline 7. & 30 & 18349 & 23 & 925 \\
\hline 8. & 12 & 18172 & 30 & 875 \\
\hline 9. & 24 & 17238 & $24 ; 12$ & 842 \\
\hline 10. & 25 & 15674 & 25 & 769 \\
\hline
\end{tabular}

In the Top 10, tables No. 5, 3, 28, 19 and 20 were the best performers both in terms of number of customers served and in terms of generalised revenue. The authors' calculations showed that five best- performing tables from the Top 10 accounted for more than half of total revenue from business and more than half of total customers served in the analysis period. This means that the potential of the other tables was not used sufficiently.

The authors carried out an experiment - two tables not included in the Top 10 were decorated to identify whether customers would choose them. Before the experiment, in the authors' opinion, the tables were not decorated in an attractive manner and did not create a feeling of being in a fancy restaurant, whereas during the experiment the tables were decorated to create a festive atmosphere. The authors used a chiffon tablecloth, as it was available and easy-to-clean, and it was easy to experiment in terms of decoration. The authors placed autumn tree leaves between tablecloth layers; apples for the decoration purpose were taken from an apple tree growing in the backyard of the restaurant. Only flowers and candles made some costs for the experiment.

Number of customers wishing to reserve a decorated table during the experiment at the BBS-Dizain Ltd restaurant

\begin{tabular}{|c|c|c|}
\hline Date & Number of decorated tables & $\begin{array}{c}\text { Number of customers wishing to } \\
\text { reserve a decorated table }\end{array}$ \\
\hline $\mathbf{1 6 . 1 0 . 2 0 1 8 .}$ & 2 & 0 \\
\hline $\mathbf{1 7 . 1 0 . 2 0 1 8 .}$ & 2 & 1 \\
\hline $\mathbf{1 8 . 1 0 . 2 0 1 8 .}$ & 2 & 7 \\
\hline $\mathbf{1 9 . 1 0 . 2 0 1 8 .}$ & 2 & 13 \\
\hline $\mathbf{2 0 . 1 0 . 2 0 1 8 .}$ & 2 & 18 \\
\hline $\mathbf{2 1 . 1 0 . 2 0 1 8 .}$ & 2 & 29 \\
\hline $\mathbf{2 2 . 1 0 . 2 0 1 8 .}$ & 2 & 11 \\
\hline
\end{tabular}

Source: authors' experiment 
During the experiment, most of the customers chose particularly the decorated tables after getting to know No extra charge had to be paid for these tables. In some cases, customers asked whether they could reserve particularly the decorated tables before making their reservations.

The data acquired during the experiment indicated that the customers preferred the decorated tables. This allows concluding that such a table enhancement is necessary for all the tables. The authors suggest applying a differentiation strategy to table decoration, i.e. currently the most demanded tables should be decorated in a classical manner, while the least demanded ones - in a fancy manner in order to arouse a wish in customers to choose them.

Such a table enhancement might increase the number of customers served and revenue for the enterprise.

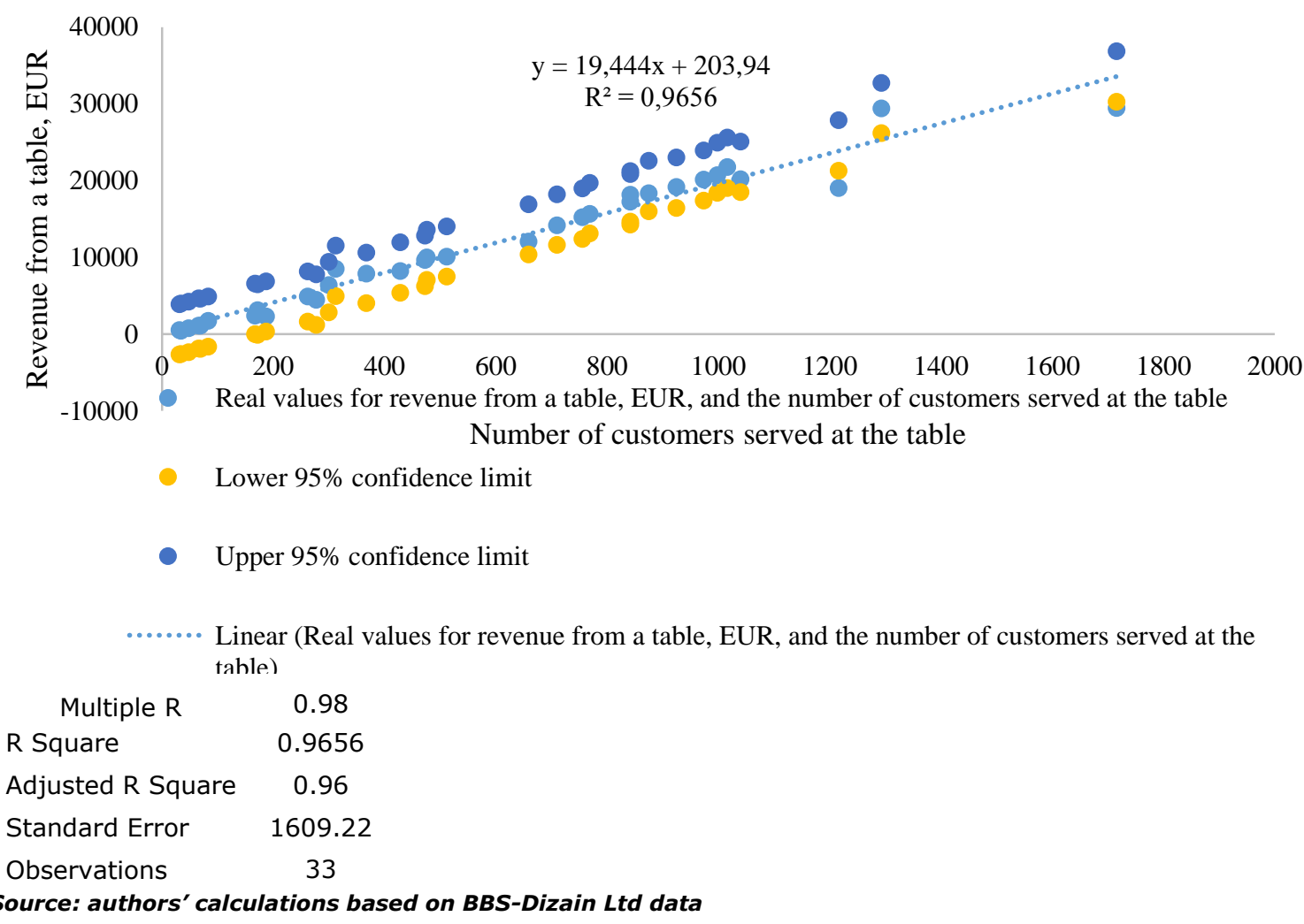

Fig. 2. Scatterplot for an association between BBS-Dizain Ltd revenue from a table (EUR) and the number of customers served at the table (01.01.-31.08.2018), the regression line, the equation and the range of values

To identify a causal association for the dependent variable (revenue generated from a table) if the independent variable (number of customers served at the table) changes by one unit, the authors did a single-factor regression analysis. The results are presented in Figure 2.

The correlation coefficient showed that if the number of customers served at the table changes by one standard deviation of the mean, one can expect that revenue might increase by 0.983 standard deviations. The determination coefficient equalled 0.9656 , which indicated that the factor of the equation explained $96.56 \%$ of the dispersion of the dependent variable.

Based on the equation acquired:

$$
y=19.444 x+203.94
$$

Where:

$y$ - total revenue from a table (EUR);

$x$ - number of customers served at the table, 
the authors conclude that an increase in the number of customers served at a table by one,

\section{revenue from the table rose by EUR 19.44.}

The confidence interval at a $95 \%$ confidence level for the regression line slope coefficient for the sample was in the range of $18.10 \leq \beta \leq 20.79$. This means that at a $95 \%$ confidence level or 0.05 significance level, one can expect the regression coefficient is not smaller than 18.10 and not larger than 20.79. It follows that an increase in the number of customers served at a table by one person results in an increase in revenue by not less than EUR 18.10 and not more than EUR 20.79. A test of the statistical significance of the regression coefficient showed that at a $95 \%$ confidence level, the dependent variable (revenue) depended on the independent variable (number of customers served at a table). The test of the regression equation hypotheses revealed that one can assume at a $95 \%$ confidence level that the linear equation explained variable changes statistically significantly.

\section{Conclusions, proposals, recommendations}

1) For the customers of BBS-Dizain Ltd, the most important restaurant performance components were as follows: quality of dishes, order completion time, personnel attitude and room tidiness, while moderately important components were as follows: the payment system (2.87), interior design (3.02) and room arrangement (3.44). Table decoration (2.93) and order completion time (3.49) were rated the lowest by the BBS-Dizain Ltd customers. The average rating of the quality of restaurant services was high -4.48 points.

2) The BBS-Dizain Ltd customers were satisfied with the overall quality of restaurant services (customer satisfaction index $=88$ ) as well as some performance components, particularly room interior design, room arrangement, room tidiness and the payment system.

3) Both the customers and the employees of BBS-Dizain Ltd were unanimous regarding enhancement of table decoration. The customer satisfaction index for table decoration was very low (index=13).

4) The authors recommend the management of BBS-Dizain Ltd to apply a differentiation strategy to table decoration: currently the most demanded tables should be decorated in a classical manner, while the least demanded ones - in a fancy manner in order to arouse a wish in customers to choose them.

5) The authors recommend the management of BBS-Dizain Ltd to perform two assessments of the quality of services provided and consumer satisfaction by using the consumer satisfaction tree components identified by the present research in order to contribute to continuous enhancement of performance and competitiveness of the enterprise.

\section{Bibliography}

1. Babris, S., Kalkis, H., Murnieks, J., Piekuss, U. (2016). LEAN risinājumi efektīvākam biznesam (LEAN Solutions for Efficient Business). Monograph. Riga, $187 \mathrm{p}$.

2. BBS-Dizain Ltd. data.

3. Kane M.M., Ivanov B.V., Koreskov V.N., Shirtladze A.G. Sistemi, metodi i instrumenti menedzmenta kacestva. (Systems, Methods and Instruments for Quality Management. Textbook for universities). Saint Petersburg, 2009. 560 p.

4. Linina, I. (2018). Ka piesaistit un noturet pirceju (How to Attract and Retain a Customer). Monograph. Riga: Turiba University. 6. p. 